\title{
Research on Construction of Integrative Geographical Data in Digital City Management: A Case Study of Zhengzhou City
}

\author{
Wang Zhaohui ${ }^{1, a}$ \\ ${ }^{1}$ No.29, Xueyuan Road, Haidian District, China University of Geosciences, Beijing, China \\ awmornlight@outlook.com
}

Keywords: digital city management, integrative process, geographical data construction, Zhengzhou City

Abstract. Based on the geographical data construction requirements of digital city management, current situation of fundamental geographical data and city management resources, and demands for such kind of data from land and planning department in Zhengzhou, we presented an integrative process for constructing digital city management geographical data. The process was designed and operated according to the connection of aerial survey of 1:500 topographic map, 1:1000 DOM production, urban components and geocodes survey, and integrated database construction. The integrated process makes full use of the interaction in these operation procedures, and could ensure fulfillment of city fundamental geophysical data, components data collection and database construction in large area in short period. The practice showed that the integrated geographical data construction process reflected the logical connection and possibility of sharing among data, it could accelerate the progress of data construction, widen its content, and ensure its quality.

\section{Introduction}

The digital city management pattern, which is the new way of combining 10000-meter-unit grid administration method and city components administration method, refines the space of city management and locates the components precisely. It constructs two axes system of supervision center and dispatch center, redefines the city management process, and finally realizes the city management pattern more precise, more efficient and all time, all position [1]. This new pattern promotes the course of digitalization, refinement and modernization in China [2]. The digital city management requires a set of fundamental data and thematic data as its support [3], so generally data construction should be the first step.

There are a lot of differences in constructing fundamental geographical data among cities. In some developed cities, such as Beijing and Shanghai, the updating cycle of data is very short, the extent of it is wider, and quality is better. And many cities in other area, especially in mid-western China, the updating cycle is usually more than 10 years, and the extent and quality couldn't meet the demand of digital city management.

The basic requirement of data construction in digital city management is fulfill the demand for fundamental space data and thematic data, and ensure the construction and operation of the system. By combining the geographical data construction requirements of digital city management, current situation of fundamental geographical data in Zhengzhou, and demands for such kind of data from land and planning department, this paper presented an integrative constructive process in order to fulfill the urgent demand for fundamental geographical data. According to the relevant standards of Department of Building and Housing [4], components code consists of 16 digits, representing district codes, class codes, subclass codes and serial numbers.

\section{The content of data construction in digital city management}

The content of geographical data includes 1:500 fundamental geographical data, 1:1000 DOM data, 1:2000 topographic map, 1:500 city management base map, 1:500 components data, geocode data, and unit-grid data. 
Collection and Database Building of Fundamental Geographical Data. The content of fundamental geographical data in Zhengzhou includes: (1) 1: 500 topographic map with full elements as base map; (2) DOM data with $0.12 \mathrm{~m}$ resolution or higher; (3) administrative map which includes district, street and community boundary, this is the basis of unit-grids.

Survey and Database Building of city components data. Components are the subjects of city management, mainly include public utilities, such as road, bridge, water, electricity, gas heating, park and greenbelt, also include some nonpublic facilities, such as doorplates, advertising boards.

The database of city components stores all the objects of management; it is the central database in digital city management system.

According to the relevant standards and requirements of Ministry of Housing and Urban-Rural Development ${ }^{[4]}$, the codes of components consist of 16 digits, representing district code, class code, subclass code and serial numbers.

Survey and database building of geocode data. According to the standards and requirements of Ministry of Housing and Urban-Rural Development ${ }^{[5]}$, geocode data can be classified as names of administrative region, plots, communities, streets, doorplates, POI (Points of Interest) addresses and so on.

Division and database building of unit-grid data. Unit-grids are minimum management area in digital city management system, which divide the administrative region into a number of different units based on the principles of local management, space distribution and convenience by using grid technology.

According to the standards and requirements of Ministry of Housing and Urban-Rural Development ${ }^{[6]}$, unit-grid consists of 12 digits, and can be classified as district code, street code, community code and serial number.

\section{The Design and Operation of Integrated Geographical Data Construction}

The Thinking and Process Design of Integrated Geographical Data. Data construction for digital city management in Zhengzhou had to fulfill the requirements of the system and needs of data sharing, so we must adopt a new process during the whole data construction.

According to the contents and technical points of data construction, in order to increase efficiency, we could cross-operate different procedures, accelerate progress and check each other's quality. There are some achievements we could use during all the process: (1) Basic control net. This is the foundation of geographical data mapping and components surveying. New basic control net needs to be fulfilled the requirements of current mapping and transformation between new and old coordinates system. And the new control net could be used to examine the quality of data achievements in current project, furthermore, could be used as standard and integrated control net achievements in the long-term in Zhengzhou city; (2) Building attributes and geocodes. There are some differences between building attributes and geocodes, for example, the points in surveying building attributes are materials and floors, and that in collecting geocodes are addresses information, but these two processes both need to check the buildings one by one. So they could be operated in the same time. (3) Supplementary field work of aerial surveying and components surveying. Field work of aerial surveying involves a lot of supplementary work, and meanwhile, some attributes of components also the same as topographic map data which come from aerial surveying production. So they could combine based on this. (4) Different processes are inter-related and could be cross-checked, for example, basic geographical database construction and city components database construction, and they could combine effectively.

The technologies of geographical data construction in digital city management make a breakthrough comparing with traditional construction pattern in separate way. The integrated geographical data construction process is formed by studying the interaction among different procedures and stages, and is shown in fig. 1. 


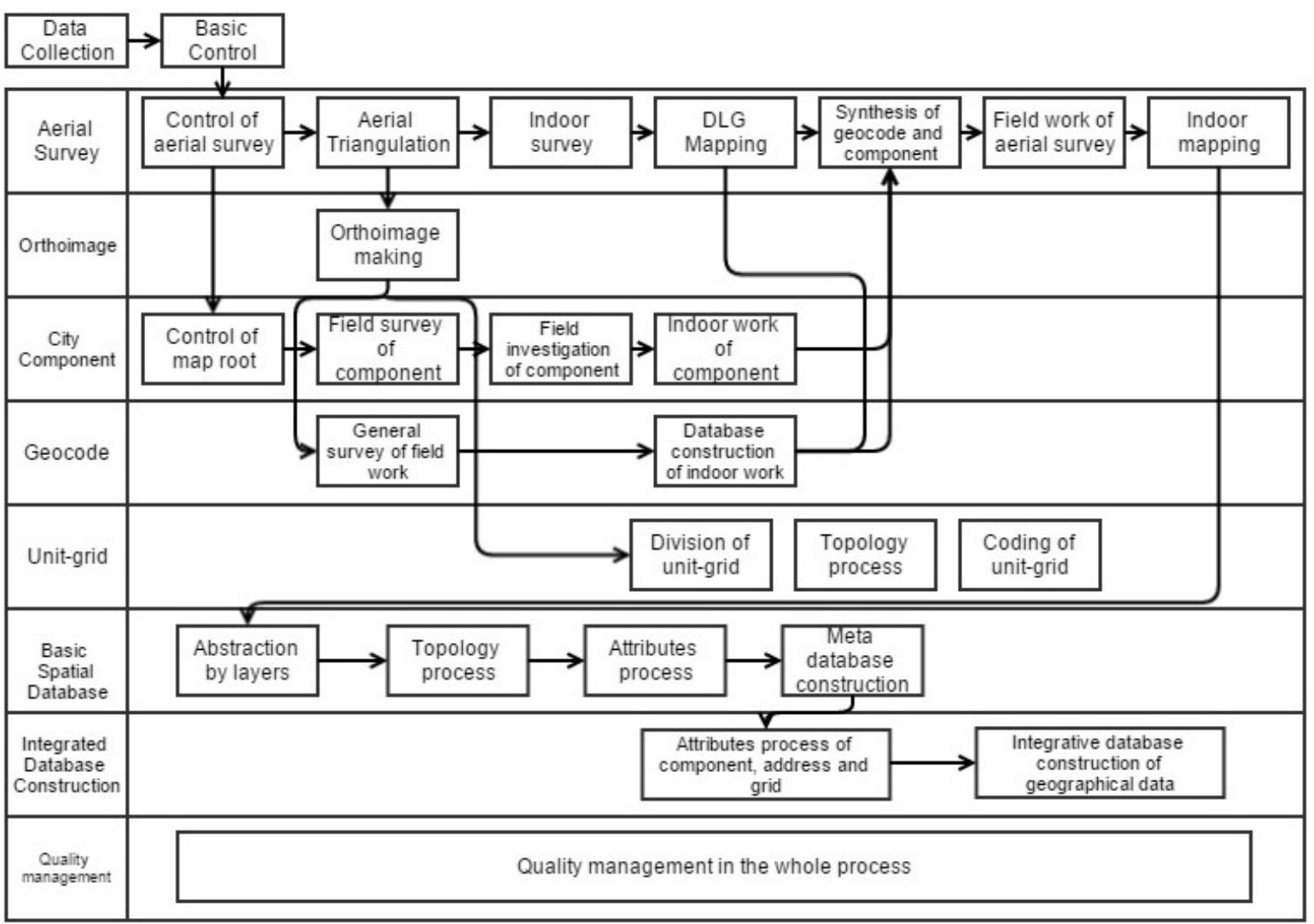

Fig.1. General frame of database construction of digital city management

The Operation of Integrated Data Construction. One of the most important procedures is the combination of indoor work of aerial survey and component database construction, means that the operation is proceeded according to the sharing relation between purposes of data construction and data ${ }^{[7,8]}$. The basis of the design of processes are: (1) the combination of component database and fundamental geographical database construction could reduce workload; (2) after inputting the attributes of component, some kinds of indoor work, such as layering, assign symbols, could be straight proceeded, and this also reduce some workload. For the convenience of survey and database construction of component, the integrative system of component survey and database construction is developed ${ }^{[9,10]}$, shown in fig. 2 .

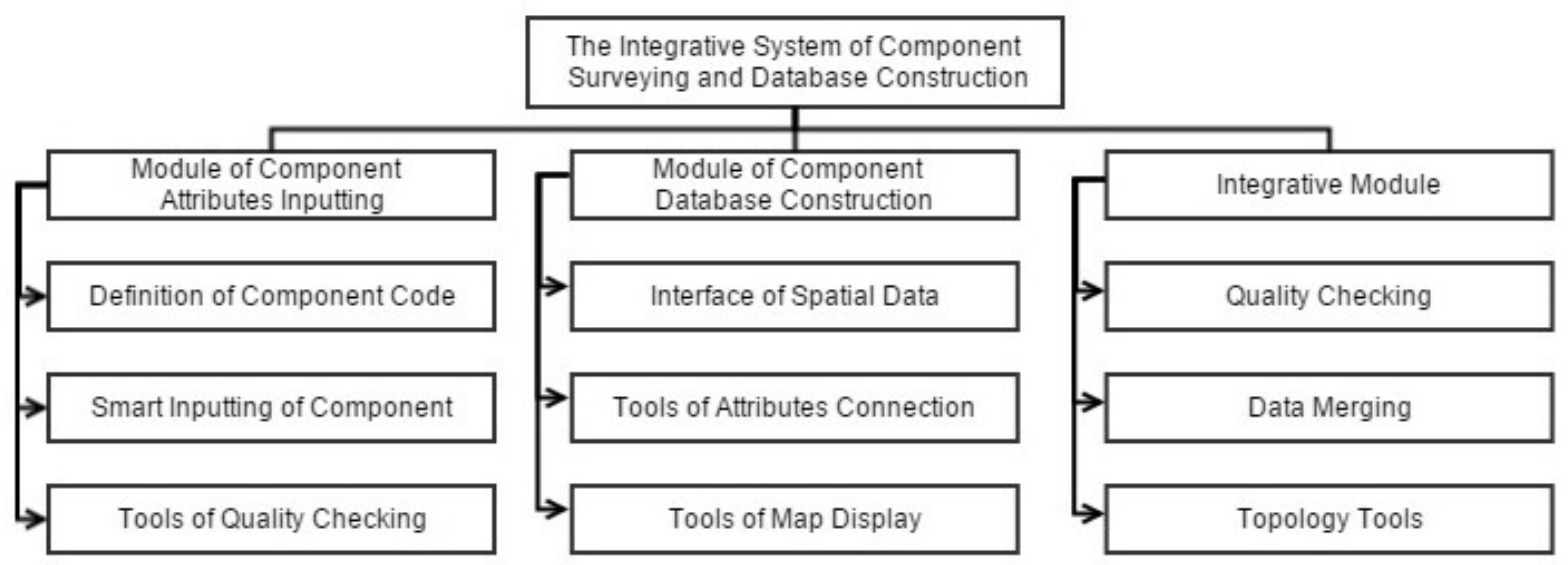

Fig.2. Modules of integrative system of database construction and city components 


\section{Conclusions}

The construction project department of digital city management system adopted the integrative geographical data construction process this paper presented, and accomplish the project in short time. Meantime, it fulfills the requirement of fundamental geographical data from some other related departments. And this project also lays the foundation of constructing universal data exchange platform ${ }^{[11]}$. The practice has proved that the integrative geographical data construction process fully uses the logical relations and sharing possibility of different types of data, it accelerates the progress of data construction, widens the content and guarantees the data quality. This is a data construction pattern could be used for reference.

\section{References}

[1] Min Sun, Ainai Ma and Jun Chen. Review on Three-Dimensional City Model Research, Journal of Remote Sensing. Vol.6, No.2 (2002). (In Chinese)

[2] S. Greuter, J. Parker, N. Stewart, G. Leach. Real-Time Procedural Generation of 'Pseudo Infinite' Cities. GRAPHITE (2003).

[3] L. Chia-Cheng. A Study of Virtual Buildings and Cities Generation. A Thesis Submitted in Partial Fulfillment for the Requirements of Master Degree in National Dong-Hwa University(2009).

[4] Deren Li, Mingjun Peng and Zhenfeng Shao. The design and implementation of city grid management and service system based on spatial database. Wuhan university journal. Vol.31, No.6 (2006). P.471-475. (In Chinese)

[5] Xiaobo Wang, Jian Zhang and Chengjie Wang. The Primary Exploration about Methods of Simulating Urban Development Using CA Models In Haikou City. City Planning, Vol.126, No.18 (2002). (In Chinese)

[6] Ningrui Ding, Bing Ding. Cellular Automata and Their Application to Modeling Spatial-Temporal Process of Urban Development, Journal of Wuhan University of Hydraulic and Electric Engineering. Vol.34, No.6 (2001). (In Chinese)

[7] Yixing Zhang. Urban Geography (Commercial Press, Beijing 1997). (In Chinese)

[8] Xuejun Deng. Virtual City: Techniques Scheme and Applications, Journal of surveying and mapping. Vol.12 (2001). (In Chinese)

[9] Qingquan Li, Biwu Yang. Real-Time Acquisition, Modeling and Visualization of 3D Space Data (Wuhan University Press, Wuhan 2003). (In Chinese)

[10] Guo'an Tang, Xuejun Li and Guonian Liu. Principles and Methods on DEM and Geoscience Analysis (Science Press, Beijing 2006). (In Chinese)

[11] Ping Chen. New pattern of grid city management (Beijing University Press, Beijing 2006). P. 128-129. (In Chinese) 